\title{
Congenital heart disease in the first week of life
}

\author{
Graham A. H. Miller \\ From the Brompton Hospital, Fulham Road, London
}

\begin{abstract}
From Fanuary 1970 to December 1973, II 8 infants were submitted to cardiac catheterization during the first week of life. Of these, III had primary cardiac anomalies, the commonest malformation being complete transposition (34\%). Mortality caused by catheterization was only $I \cdot 7$ per cent, and though only $3 I$ per cent of these infants are still alive over 50 per cent of the original group had theoretically correctable lesions while only II per cent had totally inoperable malformations. It is concluded that a policy of complete and early investigation and surgical treatment is justified by the high potential salvage; some of the factors that influence mortality are identified and it is suggested that with early complete correction an increased salvage rate is to be expected.
\end{abstract}

The high mortality from congenital heart disease in the first month and especially the first week of life has resulted in a plea for early investigation and surgical intervention in order to achieve the best possible salvage 'despite the high risk of investigation' in this group (Lambert, Canent, and Hohn, 1966). While fully supporting a policy of early and full investigation and early surgical intervention when appropriate, it seemed worth while reviewing our experience to see just what was the risk of catheterization in neonates with severe congenital heart disease, and to try and identify problems of management which, if solved, would result in an important increase in salvage rate. To this end the records of all neonates submitted to diagnostic catheterization in the first week of life were reviewed. The 4-year period January 1970 to December 1973 was chosen, since over this period a computer-based data logging and retrieval system had been used to record details of all catheterizations performed at the Brompton Hospital. Recently Varghese and coworkers (Varghese et al., 1969) have reported their experience with 100 infants catheterized during the first month of life over a $4 \frac{1}{2}$-year period. With this exception there appear to be no other reports of a similarly extensive experience and none confined to the group aged less than I week. Reported here are the details of II8 such neonates, of whom III had congenital heart disease and may reasonably be supposed to be those with the most severe forms of congenital heart disease and with the highest natural mortality.

Received 3 June 1974 .

\section{Methods}

Cardiac catheterization was performed using conventional techniques and the pattern of study adopted was that appropriate to each individual patient's condition and clinical diagnosis. Though sedation (usually chloral hydrate $100 \mathrm{mg} / \mathrm{kg}$ ) was more commonly employed than was general anaesthesia, many very sick infants were studied under general anaesthesia with intermittent positive pressure ventilation and indeed some of the most critically ill infants were already intubated and being ventilated on arrival in the laboratory. The approach used was determined by the clinical diagnosis and included catheterization of the axillary, saphenous, and femoral veins, and retrograde arterial catheterization via the axillary artery. The aim of all studies was to achieve a complete diagnosis in the shortest possible time. Acid/ base state was determined if the patient's state gave any anxiety and was corrected where necessary. A warm water circulating pad was used to help maintain body temperature. Blood loss was minimized by the use of online reflection oximetry. Catheters were always manipulated with pressure monitoring and this together with on-line oximetry made it possible for the operator to have all pressure and saturation data available as the study progressed, thus minimizing the need for repeated catheter manipulation. Cine and (biplane) serial angiocardiography was available, and the use of video-tape recording made repeated injections unnecessary. The total amount of contrast medium 1 used only exceeded $3 \mathrm{ml} / \mathrm{kg}$ in the most exceptional circumstances.

\section{Results}

\section{Catheterization}

In the 4-year period January 1970 to December 1973

${ }^{1}$ Triosil 75 per cent. 
inclusive, I 8 infants under I week of age were submitted to diagnostic cardiac catheterization. The average weight of these infants was $3.18 \mathrm{~kg}$. Catheterization was associated with a major complication ${ }^{1}$ in 14 cases ( $11.8 \%$ ) including 2 deaths $(\mathrm{I} \cdot 7 \%)$ : in $\mathrm{I}$ infant with coarctation there was perforation of the aorta by the catheter, and the other death occurred shortly after catheterization in a moribund infant with aortic atresia.

The average duration of the procedure was $9 \mathrm{I} \cdot 6$ minutes. The object of the procedure was achieved (complete diagnosis or diagnosis complete enough for correct management) in 86.4 per cent; partially achieved (incomplete diagnosis) in 11.8 per cent, and not achieved (no diagnosis or incorrect diagnosis) in $I \cdot 7$ per cent.

\section{Diagnoses}

In 7 of the 118 cases the primary abnormality lay outside the heart: 2 infants presented with heart failure caused by a cerebral arteriovenous fistula; the remaining 5 had abnormalities of pulmonary function or of pulmonary vasculature. Of the III cases with primary cardiac anomalies the commonest condition seen was complete transposition of the great vessels (38 of III cases or $34 \%$ ) and about half of the severely cyanosed infants had this condition. The frequency of each condition found is illustrated in Fig. I and listed in Table I.

\section{Mortality}

Of the III infants with heart disease, 62 per cent were alive at I week, 45 per cent at I month, and 36 per cent at I year (Fig. 2). A further 6 children (all of whom had complete transposition) died after I

1 As defined in the co-operative study on Cardiac Catheterization: Circulation, 37, Suppl. III, I07, 1968.

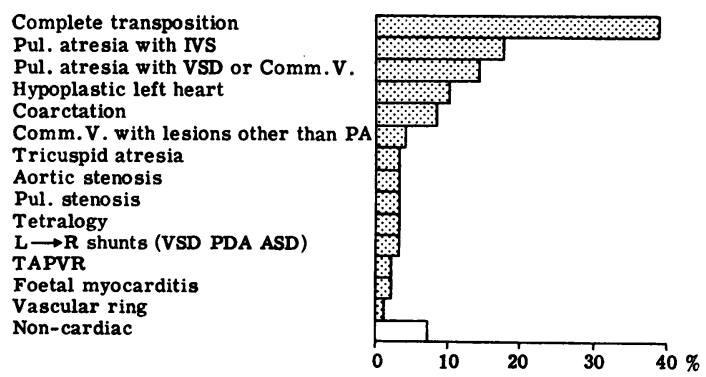

FIG. I Frequency distribution of diagnoses made in 118 infants studied by cardiac catheterization within the first week of life over the 4-year period from fanuary 1970 to December 1973.
TABLE I Diagnostic classification

\begin{tabular}{|c|c|c|}
\hline Infants with heart disease & No. & $\begin{array}{l}\text { Per cent of } \\
\text { congenital } \\
\text { heart } \\
\text { diseases }\end{array}$ \\
\hline
\end{tabular}

Complete transposition

(i) with intact ventricular septum or small ventricular septal defect $\quad 27$

(ii) with ventricular septal defect Total $\begin{array}{ll}\text { II } \\ \mathbf{3 8}\end{array}$

Pulmonary atresia with intact ventricular septum $17 \quad 15$

Pulmonary atresia with ventricular septal defect or common ventricle

I4 13

Hypoplastic left heart Aortic atresia

Mitral atresia

$\begin{array}{rrr} & 8 \\ & 2 \\ \text { Total } & \text { 10 } & 9\end{array}$

Coarctation $8 \quad 7$

Common ventricle with lesions other than pulmonary atresia

Tricuspid atresia

Aortic stenosis (critical)

Pulmonary stenosis (critical)

Tetralogy

Left-to-right shunts

Atrioventricular canal + mitral regurgitation

Persistent ductus arteriosus + ventricular septal defect + atrial septal defect I

Atrial septal defect + ventricular septal defect

$\begin{array}{lll}\text { Total } & \mathbf{I} & \mathbf{3}\end{array}$

Total anomalous pulmonary venous return

Fetal myocarditis

Vascular ring (double aortic arch)

$\begin{array}{ll}\mathbf{2} & \mathbf{2} \\ \mathbf{2} & \mathbf{2} \\ \mathbf{1} & \mathbf{1}\end{array}$

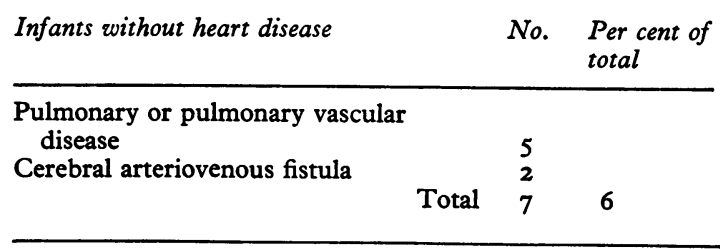

year of age, so that there are now 34 children still alive of the original I I who had primary cardiac disease $(31 \%)$. Mortality varied from 100 per cent of those with aortic or mitral atresia to none of the 3 with tetralogy of Fallot. The percentage of infants surviving at I week, I month, and I year is shown for each condition in Fig. 2. Of the 77 patients with congenital heart disease who died, $5 \mathrm{I}(66 \%)$ had some form of surgical treatment. 

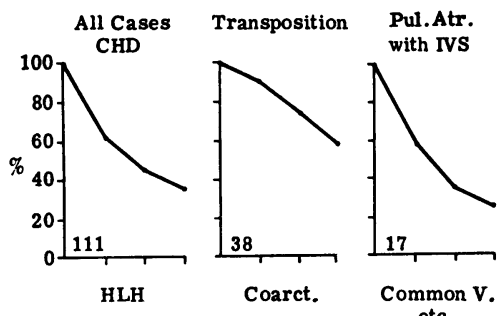

Pul. Atr. with Common V. or VSD
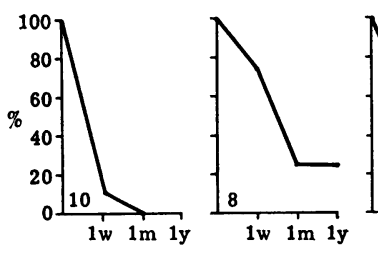

$$
\text { etc. }
$$
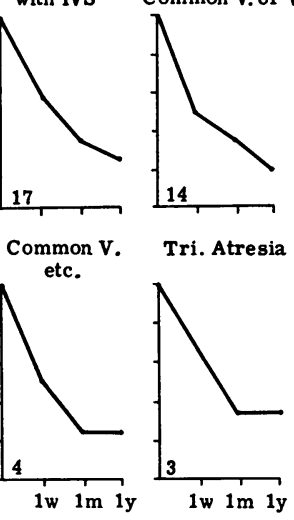

$a$
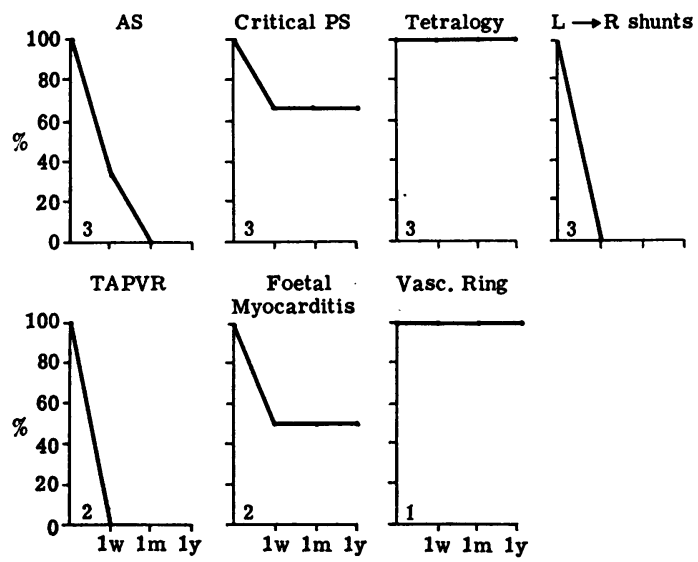

Vasc. Ring

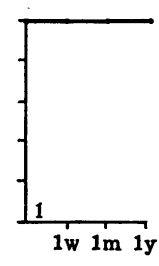

$b$
TABLE 2 Potential salvage

No. Per cent of congenital heart

disease

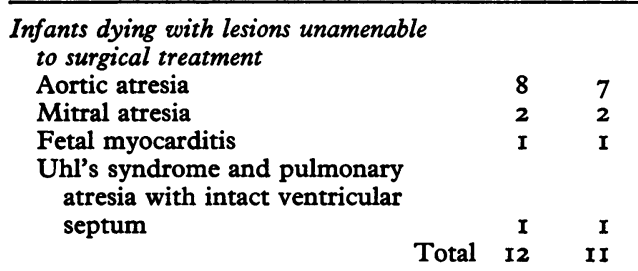

Infants dying with lesions amenable

to palliation

Pulmonary atresia with intact

Pulmonary atresia with ventricular septal defect or common ventricle

Common ventricle with lesions other than pulmonary atresia

Tricuspid atresia

$\begin{array}{rrr} & 3 & 3 \\ & 2 & 2 \\ \text { Total } & 27 & 24\end{array}$

Infants dying with theoretically

correctable lesions

Complete transposition

Coarctation

Left-to-right shunt (atrial septal defect, ventricular septal defect, persistent ductus arteriosus)

Aortic stenosis

Total anomalous pulmonary venous

return

Pulmonary stenosis

$\begin{array}{lrr} & 2 & 2 \\ \text { Total } & \mathbf{1} & \text { I } \\ & 38 & 34\end{array}$

FIG. 2 Percentage survival for all cases of congenital heart disease and for each separate condition at I week, I month, and I year. Total of III infants catheterized during the first week of life.

\section{Potential salvage}

Of the 77 infants dying with heart disease, 12 had lesions unamenable to surgical treatment at the present time, 38 had lesions theoretically amenable to complete correction (including 23 with complete transposition), and 27 had lesions amenable only to palliative surgical treatment (Table 2).

Thus of the III infants with heart disease, 31 per cent are still alive, I I per cent died with untreatable lesions, 34 per cent died with potentially correctable lesions, and 24 per cent died with lesions amenable to palliation (Fig. 3).

Of those who died with potentially correctable lesions, 60 per cent had complete transposition of the great vessels.

\section{Transposition of the great vessels}

Of the 38 patients with complete transposition catheterized in the first week of life, 15 (40\%) are still alive. Among the group as a whole 74 per cent were alive at I month and 60 per cent at I year. The best prognosis was for cases with a ventricular septal defect and no coarctation ( $84 \%$ survival at I month, $68 \%$ at I year) and the worst for patients with coarctation ( $57 \%$ and $43 \%$ at I month and I year, respectively).

Survival rates improved over the period under review; the percentage of patients alive at $I$ month was 64 per cent in 1970, 75 per cent in 1971, 80 per cent in 1972, and 83 per cent in 1973. At I year the percentage survival was 45 per cent, 50 per cent, and 80 per cent in 1970, 1971, and 1972 (follow-up too 

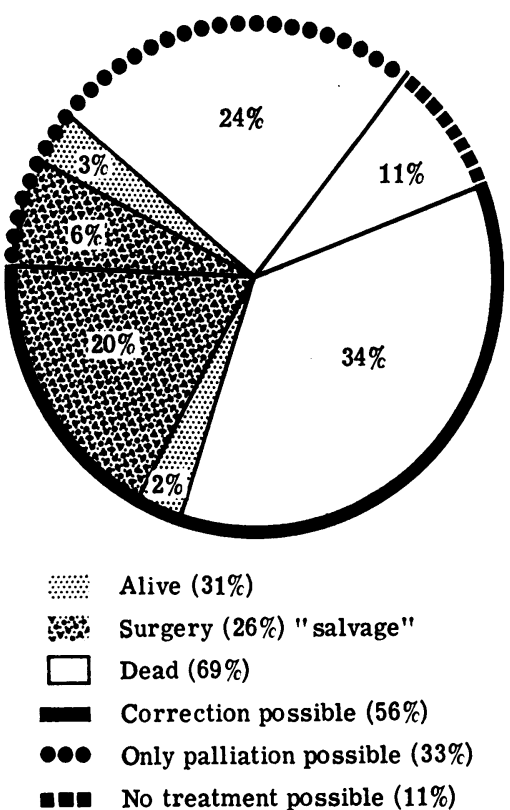

FIG. 3 The fate of III infants with congenital heart disease catheterized in the first week of life.

short for 1973) (Fig. 4). Atrial septostomy was performed successfully in all but one of the patients with an intact ventricular septum (who had an atrial septectomy) and all but 4 of those with a ventricular septal defect. When the few patients who did not have an atrial septostomy are excluded the survival rates are not altered significantly. On the other hand an additional septectomy was more frequently performed in 1971 and 1972 ( 13 of 27 patients) than in 1972 and 1973 (I of II patients).

\section{Late deaths}

Among patients with transposition there were 6 who died after I year of age: 4 of these deaths followed surgery, but 2 occurred 'at home' (or in another hospital) and a further 4 deaths occurred 'at home' in patients aged less than $I$ year. The average age of patients dying 'at home' was 8 months.

\section{Survivors}

Thirty-four patients with congenital heart disease are still alive, of whom $29(26 \%$ of all those with congenital heart disease) have had some form of palliative (including atrial septostomy) or corrective surgery: these patients may thus be regarded as representing the 'salvage' achieved in the 4-year period under review. Of the 34 patients, 23 had

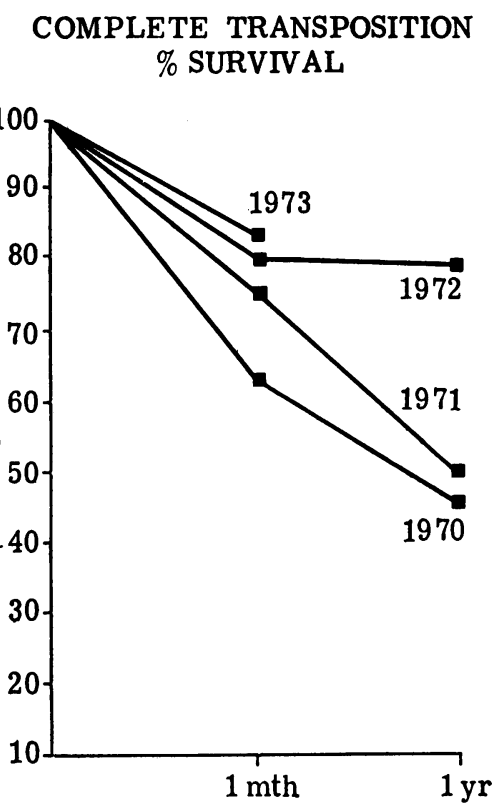

FIG. 4 Percentage survival for 38 cases of complete transposition of the great vessels catheterized during the first week of life. Survival rates are shown separately for the 4 years 1970 to 1973 at I month and I year of age.

lesions amenable to complete correction (transposition 15, coarctation 2, pulmonary stenosis 2, tetralogy 3, vascular ring I), and I made a spontaneous recovery from probable fetal myocarditis. Ten children have lesions amenable to palliation only (pulmonary atresia with intact septum 5, pulmonary atresia with ventricular septal defect or common ventricle 3 , common ventricle with lesions other than pulmonary atresia I, tricuspid atresia I) (Fig. 3).

\section{Discussion}

The risks of death resulting from cardiac catheterization have been estimated at 0.45 per cent (Braunwald and Gorlin, I968) when all patients are considered, but rise to 8.5 per cent in patients less than I week of age (Rudolph, I968). In this age group it is admittedly difficult to distinguish between deaths resulting from catheterization and those to be expected as part of the natural history of rapid deterioration and death, which is to be expected in many instances. Moreover, surgery frequently follows closely upon catheterization, thus further complicating assessment of deaths to which 
catheterization has contributed. These points have been emphasized by Varghese and co-workers (Varghese et al., 1969) who, in 1969, reviewed data on 100 patients catheterized during the first month of life. These authors found that 29 per cent of the infants studied were dead within 24 hours, and while surgery had been attempted in 10 , there were still 6 whose condition became grave at the end of the study. The series of patients reported here were all studied during the first week of life; none of the patients died on the catheterization table, but 2 died shortly after the study. In one instance death occurred in a moribund infant with aortic atresia, but in the other death was caused by an accident during catheterization when the aorta was perforated by the catheter. These 2 deaths represent a mortality of 1.7 per cent. Thus while accepting that the risks of study in this age group are certainly higher than the risk for all patients we believe that the risks of catheterization per se may not be as high as has been suggested - they are, in fact, acceptably low.

Many factors can contribute to reducing the risk of catheterization. The procedure should only be carried out by an experienced team making use of sophisticated equipment designed to reduce the duration and increase the safety of the study. In this connexion, the average duration of the study for the infants reported here was 91.6 minutes; this relatively long time reflects the large number of patients with complete transposition, in whom the diagnostic study was followed by atrial septostomy, as well as the need on many occasions to develop biplane serial films before concluding the study. It is surprising, therefore, that the co-operative study on cardiac catheterization (Braunwald and Gorlin, 1968) found that only $I \cdot 9$ per cent of all studies took less than I hour, and only 36 per cent took less than 2 hours, the average duration of the studies reported being $2 \frac{1}{2}$ hours. It is clear that the duration of catheterization can be significantly reduced below these times, and we feel that this is a desirable aim and may contribute significantly to reducing the risks of the study, particularly in sick neonates prone to hypothermia and acidosis.

If, then, the risks of catheterization are acceptably low and the natural mortality high, a policy of aggressive investigation and treatment is worth while providing there is a significant potential salvage. This study clearly demonstrates that the potential salvage is high; though the actual salvage rate achieved was only 26 per cent, only II per cent had lesions for which nothing could be done and no less than 56 per cent had lesions theoretically amenable to complete correction. This estimate is obviously only approximate, for a number of reasons. Firstly, lesions have been defined as potentially correctable or amenable to palliation, solely on the basis of the anatomy; other factors such as the condition of the infant at the time of referral, and the influence of other lesions (e.g. birth trauma, other congenital abnormalities) have been ignored. Secondly, the definition of what is correctable and what is only amenable to palliation is open to argument, and may change with the development of new surgical techniques. Thus, in the present study the 3 infants with critical aortic stenosis have been included in the group with potentially correctable lesions; however, these patients are in many ways similar to those with aortic atresia; there may be right-to-left shunting through the patent ductus, and the left ventricle and aorta may be very small. Certainly all 3 patients died within the first week of life as did all of those with aortic atresia. On the other hand, patients with pulmonary atresia and intact ventricular septum with a small right ventricle have been classified as amenable to palliative treatment only. In our experience (Miller et al., 1973) this is true, there being a dramatic increase in survival when a policy of palliation (aorto-pulmonary shunt plus atrial septectomy or septostomy) was adopted. Others, however, have reported successful correction by pulmonary valvotomy (Bowman et al., 1971). The most difficult group to classify was the group with a common ventricle (or ventricular septal defect) and pulmonary atresia, and the group with common ventricle and lesions other than pulmonary atresia. Successful correction of certain types of pulmonary atresia has been reported (Ross and Somerville, 1966) as has the correction of common ventricle (Edie et al., 1973). However, these two groups of patients included many with very complex heart disease, notably the asplenia syndrome with dextrocardia or isolated laevocardia; transposition was common, and other associated lesions included aortic interruption, common atrioventricular valve, coarctation, mitral atresia, and pulmonary stenosis. For these reasons, these two groups have been classified as amenable to palliative surgery only.

The final question that needs answering is how the actual salvage rate might be increased. In 1973, Rowe and Vlad reviewed the problem of heart disease in the newborn and concluded that though the overall salvage remained low, encouraging advances had been made in transposition and in ventricular septal defect and some improvement had taken place in the management of pulmonary atresia and pulmonary stenosis and in tetralogy of Fallot.

The patients with transposition of the great vessels are numerically the most important group, and form 63 per cent of those with potentially 
correctable lesions. If we had lost no case of transposition our salvage rate would have increased from 29 to 50 per cent. In this connexion, there was encouraging evidence that the survival rate increased over the 4-year period, probably reflecting improved overall management. The study highlighted one area where salvage might be improved since the group with transposition included a significant number who died over the age of 6 months and a significant number who died 'at home' despite apparently successful palliation. There is thus a need for close supervision even of apparently well infants, and, since further palliation by atrial septectomy did not appear to prevent these late deaths, it seems that a policy of early correction is indicated, even as early as 6 months of age (Rowe and Vlad, 1973). Patients with isolated left-to-right shunts (atrial septal defect, ventricular septal defect, persistent ductus arteriosis) do not commonly present with distress in the first week of life and such patients formed only 3 per cent of the patients reported here: however, all died. This experience is in contrast to that of Varghese and co-workers (1969) who found isolated left-to-right shunts in 20 per cent of roo infants catheterized under I month of age, only I of whom died. This contrast emphasizes the need to review separately those presenting in the first week of life at which time persistence of the fetal pattern of high pulmonary vascular resistance prevents the development of a large leftto-right shunt. As has been emphasized by Rudolph (1970), only obligatory shunts are independent of pulmonary vascular resistance and may thus be expected to present earlier in life. In this group, palliative pulmonary artery banding is of no value. Of our 3 infants, I had an obligatory shunt (atrioventricular canal with gross mitral incompetence) and both the others had an atrial septal defect in addition to a ventricular septal defect. Thus salvage in this (small) group will probably require complete correction within the first week of life, and palliative pulmonary artery banding is unlikely to be effective.

Two other conditions need discussing in some detail. Thus, there were 6 infants with coarctation who died. One of these died of a complication of catheterization, and one was moribund on admission and died before operation could be undertaken. The remaining 4 patients had additional lesions causing a large left-to-right shunt (atrial septal defect + ventricular septal defect, I case; ventricular septal defect, 2 cases; atrial septal defect, I case). Thus in this condition, salvage appears to depend not only on repair of coarctation but also on the need for correction of these associated left-to-right shunts (Rowe and Vlad, 1973).

Finally, though successful repair of total anomal- ous pulmonary venous return is being reported with increasing frequency, the mortality remains high in the group under I month of age and in those with pulmonary artery pressure in excess of systemic. Behrendt and co-workers (1972) reported no survivors of 7 operated on under 6 weeks of age, and 7 of 8 with right ventricular pressure between 100 and I50 per cent of systemic also died. Both of our cases had right ventricular pressure in excess of systemic and one had infradiaphragmatic total anomalous pulmonary venous return.

In conclusion, infants with congenital heart disease who are in distress in the first week of life remain a group with a high mortality; however, very few have totally inoperable lesions and more than half have correctable lesions. Catheterization is essential for correct management and need not be associated with a high risk; at the same time there are indications that survival can be, and has been, improved. This improved survival is likely to result from a policy of early complete surgical correction. Optimism, not pessimism, is the result of reviewing the problems posed by this difficult group of patients.

\section{References}

Behrendt, D. M., Aberdeen, E., Waterston, D. J., and Bonham-Carter, R. E. (1972). Total anomalous pulmonary venous drainage in infants. Clinical and hemodynamic findings, methods, and results of operation in 37 cases. Circulation, 46, 347.

Bowman, F. O., Malm, J. R., Hayes, C. J., Gersony, W. M., and Ellis, K. (197I). Pulmonary atresia with intact ventricular septum. Fournal of Thoracic and Cardiovascular Surgery, 6I, 85.

Braunwald, E., and Gorlin, R. (1968). Co-operative study on cardiac catheterization: total population studied, procedures employed and incidence of complications. Circulation, 37 and 38, Suppl. III, 8.

Edie, R. N., Ellis, K., Gersony, W. M., Krongrad, E., Bowman, F. O., and Malm, J. R. (1973). Surgical repair of single ventricle. Fournal of Thoracic and Cardiovascular Surgery, 66, 350.

Lambert, E. C., Canent, R. V., and Hohn, A. R. (1966). Congenital cardiac anomalies in the newborn. A review of conditions causing death or severe distress in the first month of life. Pediatrics, 37, 343.

Miller, G. A. H., Restifo, M., Shinebourne, E. A., Paneth, M. Joseph, M. C., Lennox, S. C., and Kerr, I. H. (I973). Pulmonary atresia with intact ventricular septum and critical pulmonary stenosis presenting in first month of life. Investigation and surgical results. British Heart fournal, 35, 9.

Ross, D. N., and Somerville, J. (1966). Correction of pulmonary atresia with a homograft aortic valve. Lancet, 2, 1446.

Rowe, R. D., and Vlad, P. (1973). Diagnostic problems in the newborn. Origins of mortality in congenital cardiac malformation. In Heart Disease in Infancy. Diagnosis and Surgical Treatment, p. 3. Ed. by B. G. Barratt-Boyes, J. M. Neutze, and E. A. Harris. Churchill Livingstone, Edinburgh and London. 
Rudolph, A. (1968). Co-operative study on cardiac catheterization: complications occurring in infants and children. Circulation, 37 and 38, Suppl. III, 59.

Rudolph, A. M. (1970). The changes in the circulation after birth. Their importance in congenital heart disease. Circulation, 41, 343.
Varghese, P. J., Celermajer, J., Izukawa, T., Haller, J. A., and Rowe, R. D. (1969). Cardiac catheterization in the newborn: experience with 100 cases. Pediatrics, 44, 24.

Requests for reprints to Dr. Graham A. H. Miller, Brompton Hospital, Fulham Road, London $\mathrm{SW}_{3} 6 \mathrm{HP}$. 